\title{
A Finite Element Model for 2-Dimensional Slice of Cast Strand
}

\author{
Heung Nam HAN, Jung-Eui LEE, ${ }^{1)}$ Tae-jung YEO, ${ }^{2)}$ Young Mok WON, ${ }^{2)}$ Kyung-hyun KIM, ${ }^{3)}$ Kyu \\ Hwan $\mathrm{OH}^{2)}$ and Jong-Kyu YOON ${ }^{2)}$
}

Sheet Products \& Process Research Team, Technical Research Labs., POSCO, Pohang-shi, Kyungbuk, 790-785, Korea. 1) Iron \& Steelmaking Research Team, Kwangyang Research Labs., POSCO, Kwangyang-shi, Cheonnam, 545-090, Korea. 2) School of Materials Science and Engineering and Research Institute of Advanced Materials, Seoul National University, Kwanak-ku, Seoul 151-742, Korea.

3) Technology Development Group, M/U FAB. Department, Semiconductor R\&D, Samsung Electronics, Yongin, Kyungi-Do 449-900, Korea.

(Received on July 27, 1998; accepted in final form on February 2, 1999)

\begin{abstract}
A two-dimensional thermo-elasto-plastic finite element model for the analysis of thermo-mechanical behavior of strand in continuous casting process has been developed. The model incorporates the effect of microsegregation of solute elements on hot tears using a thermo-mechanical model of mushy zone and $\delta$ and $\gamma$ phases. A finite element technique for the liquid region of the slice of strand, which can take the ferrostatic pressure due to gravity force into account, was proposed. The model successfully analyzed the thermo-mechanical behavior of the solidifying shell of slab in the mold during the solidification. The calculated results, such as the deformed geometries, the temperature history, the stress distribution and the formation of air gap between solidifying shell and mold in the continuous casting process of slab, were obtained. These were compared with the reported observations.
\end{abstract}

KEY WORDS: finite element material model for liquid and mushy zone; ferrostatic pressure; microsegregation; deformation of solidifying shell.

\section{Introduction}

The continuous casting process has been mathematically modeled to increase the understanding of the roles of important variables in the process, improve the design of continuous casting system, and eliminate casting defect. Especially, many thermo-mechanical finite element analyses had been developed to understand the deformation behaviors of the solidifying shell in the continuous casting process. ${ }^{1-11)}$

Tszeng and Kobayashi $^{4)}$ developed a finite element model to compute the thermo-mechanical state of a 2-dimensional slice of continuously cast steels in a billet casting mold. The stress state in liquid region was simulated by decreasing the elastic modulus by several orders of magnitude as temperature increases across the mushy zone. However, the volumetric deformation of the liquid region may be developed during the 2-dimensional slice simulation by the mechanical constraint such as the thermal contraction of solidifying shell and the mold taper resulting in the development of hydrostatic pressure which is independent of ferrostatic pressure.

Kelly et $a .^{5)}$ developed a finite element model to compute the thermo-mechanical state of continuously cast round billets. By striping away the liquid region from strand according to the results of the heat transfer calculation, they calculated only the stress state of solidified shell.

Kristiansson ${ }^{6)}$ simulated a billet casting, using a finite element analysis to determine the size of the shell/mold gap over the entire periphery of a 2-dimensional slice of the strand. To describe the deformation of liquid, zero stiffness at the element above the liquidus temperature was assigned and zero displacement to the corresponding nodal point was prescribed

To analyze the thermo-mechanical behavior and deformation of liquid strand in the continuous casting process, a finite element material model, which can easily simulate the mechanical behavior of liquid and its effect on the solidifying shell, is necessary.

Understanding the thermo-mechanical behavior of mushy zone during casting is very important to obtain good quality cast products because all cracks observed in continuously cast steel except transverse cracks form in this zone of low ductility. ${ }^{12-17)}$ In the earlier works, ${ }^{4-10)}$ the simplified thermo-mechanical property data based on equilibrium phase diagram were employed to calculate the stress at high temperature range without taking the deformation behavior of mushy zone into account. However, solidification of steel during continuous casting does not follow the equilibrium solidification path due to its rapid cooling rate. Therefore, the mathematical model describing the thermo-mechanical behavior of mushy zone as a function of temperature and steel composition, has to be developed to calculate the temperature and stress distributions in the solidifying shell more accurately, and to examine their influence on the formation of cracks.

The purpose of this study is to propose a thermomechanical material model which can explain the de- 


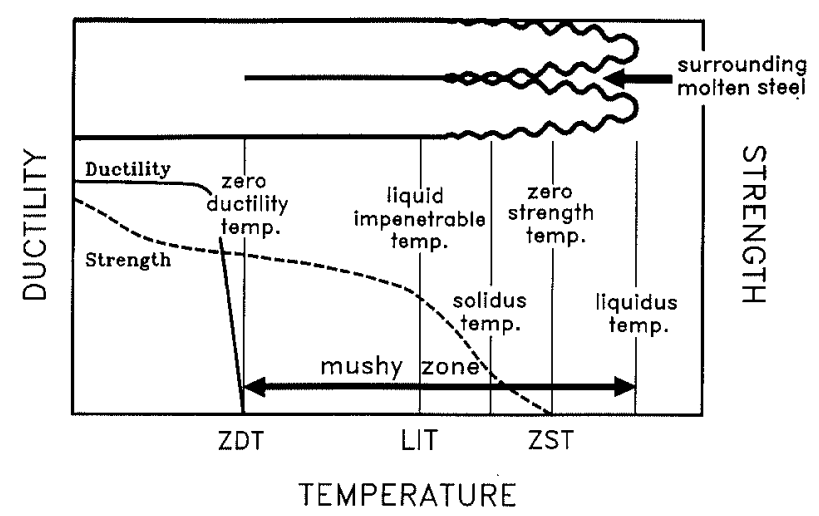

Fig. 1. Figure explaining zero ductility temperature (ZDT), zero strength temperature (ZST) and liquid impenetrable temperature (LIT).

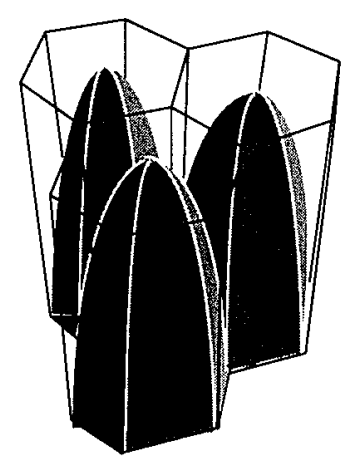

(a)

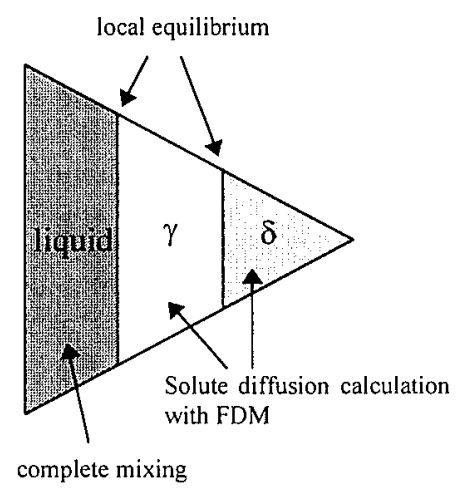

(b)
Fig. 2. (a) Schematic drawing showing the morphology of the dendrite array and (b) the transverse cross section assumed in the finite difference simulation.

formation behavior of liquid and mushy zone. Using the finite element code, we have investigated the formation of the air gap and the effect of the air gap on the temperature and stress distributions in the slab casting. The thermo-mechanical properties based on the non-equilibrium phase diagram which is calculated with microsegregation analysis program have been employed into stress and temperature field analysis.

\section{Microsegregation Analysis and Yield Criterion of Mushy Zone}

In order to determine the solid fraction in mushy zone as a function of temperature, the microsegregation of solute elements has been assessed.

The schematic diagram and the mechanical properties of solidifying interface of continuous casting steel are shown in Fig. 1. The authors calculated the solid fraction of mushy zone as a function of temperature using the finite difference method proposed by Ueshima ${ }^{11,21,22)}$ which takes into account solute diffusion in solid. Figure 2(a) shows the schematic diagram of growing dendrites in the continuously cast strand. The transverse cross section of dendrites is approximated by a regular hexagon, one sixth of which is shown in Fig. 2(b). The composition of steel and the thermo-physical data used in this calculation are given in Tables $\mathbf{1}$ and $\mathbf{2}$, respectively. Figure 3 shows the calculated solid fractions as a function
Table 1. Chemical composition of carbon steel.

\begin{tabular}{|c|ccccc|}
\hline Element & $\mathrm{C}$ & $\mathrm{Si}$ & $\mathrm{Mn}$ & $\mathrm{P}$ & $\mathrm{S}$ \\
\hline $\mathrm{W} \mathrm{\%} \%$ & 0.12 & 0.03 & 0.4 & 0.02 & 0.02 \\
\hline
\end{tabular}

Table 2. Equilibrium distribution coefficients and diffusion coefficients of elements. ${ }^{21}$

\begin{tabular}{|cccccc|}
\hline Element & $k^{\delta / L}$ & $k^{\gamma / L}$ & $k^{\gamma / 6}$ & $D^{\delta}\left(\mathrm{m}^{2} / \mathrm{s}\right)$ & $D^{\gamma}\left(\mathrm{m}^{2} / \mathrm{s}\right)$ \\
\hline $\mathrm{C}$ & 0.19 & 0.34 & 1.79 & $1.27 \times 10^{-6} \exp (-81379 / \mathrm{RT})$ & $7.61 \times 10^{-6} \exp (-134557 / \mathrm{RT})$ \\
$\mathrm{Si}$ & 0.77 & 0.52 & 0.68 & $8.0 \times 10^{-4} \exp (-248948 / \mathrm{RT})$ & $3.0 \times 10^{-5} \exp (-251458 / \mathrm{RT})$ \\
$\mathrm{Mn}$ & 0.76 & 0.78 & 1.03 & $7.6 \times 10^{-5} \exp (-224430 / \mathrm{RT})$ & $5.5 \times 10^{-6} \exp (-249366 / \mathrm{RT})$ \\
$\mathrm{P}$ & 0.23 & 0.13 & 0.57 & $2.9 \times 10^{-4} \exp (-230120 / \mathrm{RT})$ & $1.0 \times 10^{-6} \exp (-182841 / \mathrm{RT})$ \\
$\mathrm{S}$ & 0.05 & 0.035 & 0.70 & $4.56 \times 10^{-4} \exp (-214639 / \mathrm{RT})$ & $2.4 \times 10^{-4} \exp (-223425 / \mathrm{RT})$ \\
\hline
\end{tabular}

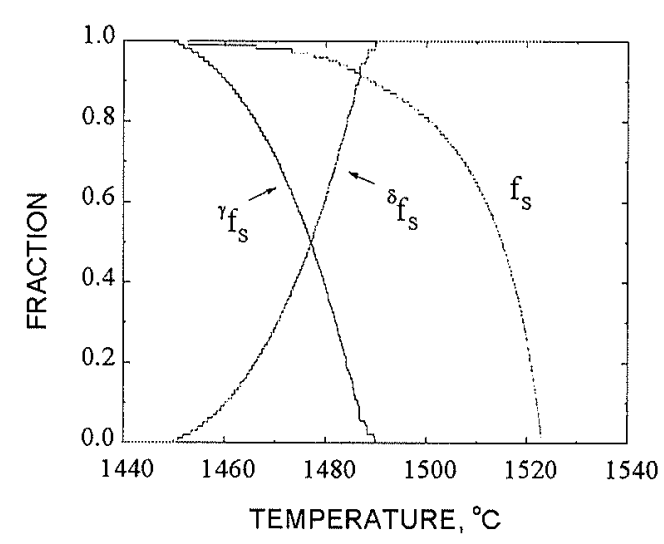

Fig. 3. Calculated solid fraction $f_{s}, \delta$-Fe fraction in solid phase ${ }^{\delta} f_{\mathrm{s}}$ and $\gamma$-Fe fraction in solid phase ${ }^{\gamma} f_{\mathrm{s}}$ as a function of temperature for $0.12 \mathrm{wt} \% \mathrm{C}$ carbon steel.

of temperature during solidification of the given steel. Calculation was carried out at a cooling rate of $0.17 \mathrm{~K} / \mathrm{s}$ and at a dendrite arm spacing of $1000 \mu \mathrm{m} .{ }^{11,20)}$ In the figure, $f_{\mathrm{s}}$ is solid fraction, ${ }^{\delta} f_{\mathrm{s}}$ and ${ }^{\gamma} f_{\mathrm{s}}$ represent $\delta$-Fe and $\gamma$-Fe fractions in the solid phase, respectively. The temperature at which the steel is fully solidified i.e. ZDT, was calculated to be $1450^{\circ} \mathrm{C}$, which is about $43^{\circ} \mathrm{C}$ lower than the solidus temperature given from $\mathrm{Fe}-\mathrm{C}$ binary equilibrium phase diagram.

In order to describe the thermo-mechanical behavior of the mushy zone between ZDT and ZST, the concept of yield criterion ${ }^{23-28)}$ for porous metals was used. The relative density, critical relative density and yield stress of porous metal in the yield criterion have been replaced by solid fraction $f_{\mathrm{s}}$, critical solid fraction ${ }^{\mathrm{c}} f_{\mathrm{s}}$ and yield stress $Y_{f_{\mathrm{s}}}$ of the mushy zone, respectively.

Figure 4 shows the relative strength of mushy zone as a function of solid fraction for various carbon steels ${ }^{11,19}$. The relative strength is defined as the ratio of strength of mushy zone to strength of fully solidified steel. Experimental data show the linear relationship between the solid fraction and the relative strength in the range of ${ }^{c} f_{s} \leq f_{s} \leq 1$ at various carbon contents. From this result, the proposed yield criterion for mushy zone gives a satisfactory result. The critical solid fraction, ${ }^{\circ} f_{\mathrm{s}}$, is determined to be 0.6491 by the best fitting of the measured data as shown in Fig. 4. ${ }^{11)}$ 


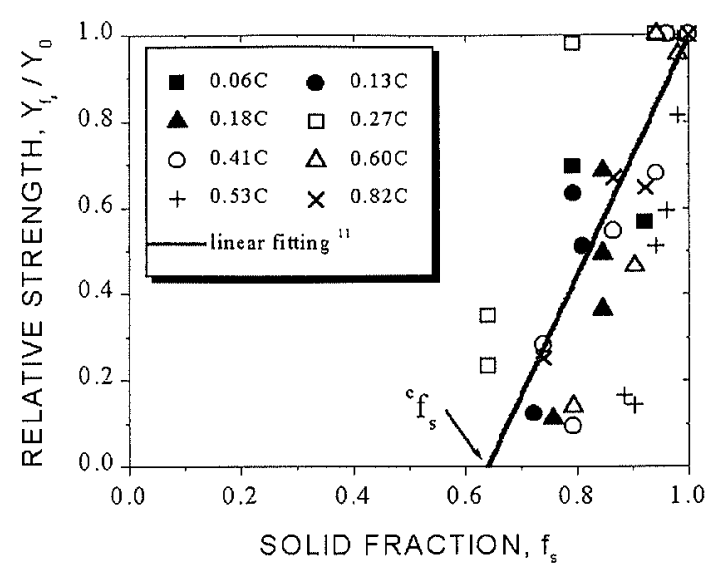

Fig. 4. Relative strength of carbon steels as a function of solid fraction.

\section{SpeciaL Procedure for Liquid Region}

At the temperature above ZST, the strand in continuous casting process should be taken as liquid region which should have a special property for a 2dimensional slice of strand. The special property includes that the stress state in liquid region should be the pure hydrostatic stress state, which is equal to the current ferrostatic pressure, and be independent of volumetric deformation in the liquid region. The volumetric deformation of liquid region during finite element analysis is inevitably developed by the thermal contraction of solidifying shell and the mold taper in the 2dimensional slice method. Figure 5 shows a schematic view of the volume change of the strand during continuous casting in a 2-dimensional slice of strand during the finite element analysis. At the beginning of solidification denoted as 'A' in Fig. 5, all the regions of strand are liquid which has zero ferrostatic pressure. In the intermediate stages of solidification denoted as ' $B$ ' and ' $\mathrm{C}$ ' in Fig. 5, the strand is solidified in part. The thermal contraction of solidifying shell and the large mold taper give rise to the reduction of area in the 2-dimensional slice of strand.

The stress state of strand is prescribed to a pure hydrostatic pressure equal to the current ferrostatic pressure when the temperature is higher than the ZST. The ferrostatic pressure, $P_{\mathrm{F}}$, acts on the interface between liquid and solidifying shell and can be expressed as follows

$$
P_{\mathrm{F}}=\rho_{1} g z
$$

where $\rho_{1}, g$ and $z$ are the density of liquid steel, the acceleration of gravity and the distance below the meniscus, respectively. Since the distance below the meniscus, $z$, changes only with the time in the finite element analysis at constant casting speed, the ferrostatic pressure is a function only of time at the constant $\rho_{1}$.

At a time $t+\Delta t$, the basic equation to be solved in the nonlinear analysis of general structural mechanics using finite element method is expressed as follows. ${ }^{29)}$

$$
{ }^{t+\Delta t} \mathbf{R}-{ }^{t+\Delta t} \mathbf{F}=\mathbf{0}
$$

where the vector ${ }^{t+\Delta t} \mathbf{R}$ stores the externally applied nodal loads, and ${ }^{t+\Delta t} \mathbf{F}$ is the vector of nodal forces that are

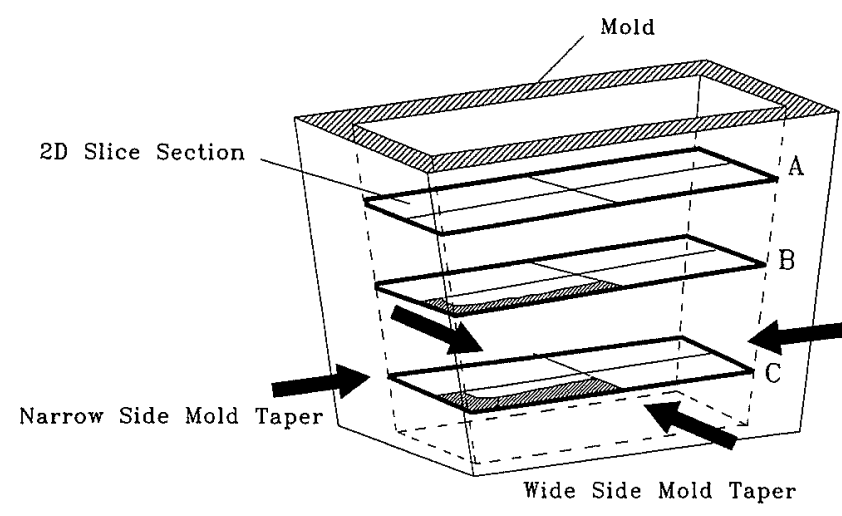

Fig. 5. Figure explaining volume reduction of liquid in continuous casting process.

equivalent to the element stress dependent only on the current ferrostatic pressure given by Eq. (1) in liquid region. And can be expressed as follows.

$$
{ }^{t+\Delta t} \mathbf{F}=\sum_{j=1}^{m} \int_{V_{j}} \mathbf{B}^{\mathrm{T}} \tau d V
$$

Where $m$ is the number of isoparametric element, $\tau$ is the stress vector and the displacement-strain matrix $\mathbf{B}$ is defined by

$$
{ }^{t} \varepsilon=\mathbf{B}^{\mathrm{T}}{ }^{t} \mathbf{U}
$$

in the finite element. Here, ${ }^{t} \varepsilon$ is strain vector.

The equations used in the modified Newton-Raphson iteration are expressed as follows

$$
\begin{gathered}
\Delta \mathbf{R}^{(i-1)}={ }^{t+\Delta t} \mathbf{R}-{ }^{t+\Delta t} \mathbf{F}^{(i-1)} \\
{ }^{t+\Delta t} \mathbf{K}^{(i-1)} \Delta \mathbf{U}^{(i)}=\Delta \mathbf{R}^{(i-1)} \\
{ }^{t+\Delta t} \mathbf{U}^{(i)}={ }^{t+\Delta t} \mathbf{U}^{(i-1)}+\Delta \mathbf{U}^{(i)}
\end{gathered}
$$

with

$$
{ }^{t+\Delta t} \mathbf{U}^{(0)}={ }^{t} \mathbf{U} ; \quad{ }^{t+\Delta t} \mathbf{F}^{(0)}={ }^{t} \mathbf{F}
$$

where superscript $i$ indicates the number of iteration. In above equations, ${ }^{t+\Delta t} \mathbf{U}$ is the displacement vector at time $t+\Delta t$ and the tangent stiffness matrix ${ }^{t+\Delta t} \mathbf{K}$ in liquid region is expressed as follows

$$
{ }^{t+\Delta t} \mathbf{K}=\sum_{j=1}^{m} \int_{V_{j}} \mathbf{B}^{\mathrm{T}} \mathbf{C}_{\mathbf{L}} \mathbf{B} d V
$$

where $C_{L}$ is the which has component of constant value. In this study, the components of $\mathbf{C}_{\mathrm{L}}$ matrix are made up of elastic constants of steel at melting point. ${ }^{5,47)}$

In Eqs. (5) and (6), the components of the vector of nodal forces ${ }^{t+\Delta t} \mathbf{F}$ and the stiffness matrix ${ }^{t+\Delta t} \mathbf{K}$ are constant over the iterations in liquid region, because the element stress and the components of $\mathbf{C}_{L}$ matrix are set to ferrostatic pressure and constant values, respectively, in liquid region at time $t+\Delta t$. Therefore, the non-linear equations to solve become linear equations in liquid region. And, the strain vector ${ }^{t} \varepsilon$ is uniform for all finite elements in liquid region, because the components of stiffness matrix are constant for all elements in liquid region.

The above proposed procedure is checked against the finite element solution of 2-dimensional hollow cylinder problem. Figure 6(a) shows the finite element mesh for 


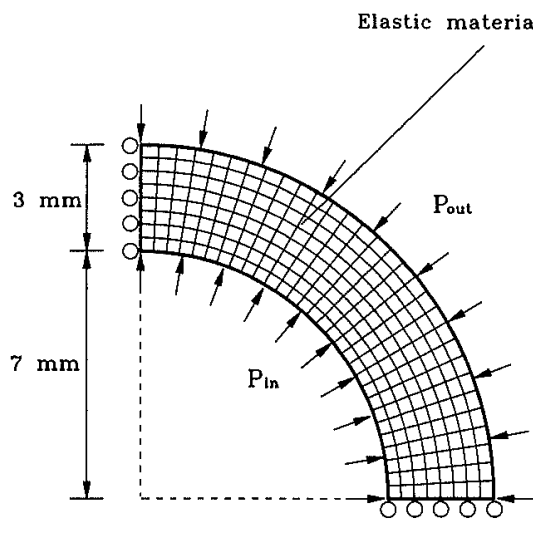

(a)

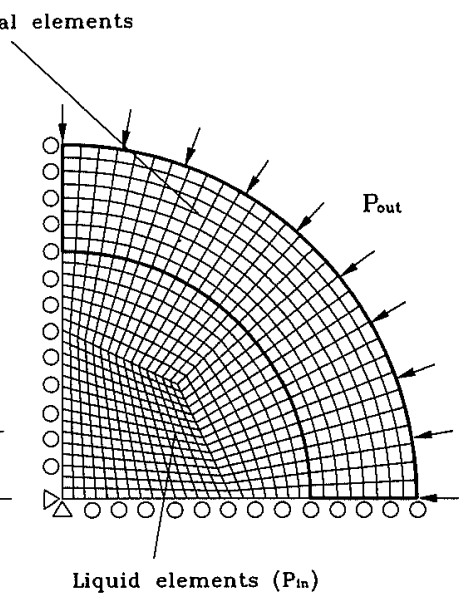

(b)

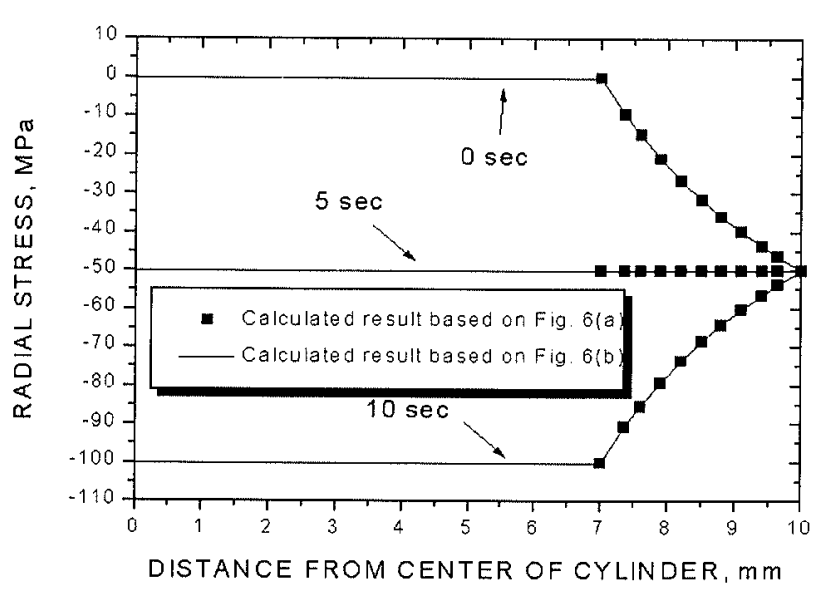

Fig. 7. Calculated radial stresses in the cylinders based on Figs. 6(a) and 6(b) as a function of time.

hollow cylinder of $14 \mathrm{~mm}$ in inner diameter and $20 \mathrm{~mm}$ in outer diameter under uniform pressures on the inner and outer surfaces. Figure 6(b) shows the finite element mesh in which the hole of cylinder is filled by the liquid elements to use the above proposed scheme. In this calculation, the uniform pressure on the inner surface of hollow cylinder in Fig. 6(a) and the internal pressure in liquid elements in Fig. 6(b) are set as follows

$$
P_{\text {in }}=10 t \quad(\mathrm{MPa})
$$

where $P_{\text {in }}$ and $t$ the pressure and the time, respectively. The uniform pressure on the outer surfaces of hollow cylinders in Figs. 6(a) and 6(b) is set to $50 \mathrm{MPa}$. The calculations are carried out under plane strain condition. The cylinder is assumed to be elastic material whose Young's modulus and Poisson's ratio are $100 \mathrm{GPa}$ and 0.3 , respectively.

Figure 7 shows the distributions of radial stress along with the distance from center of cylinder at 0,5 and 10 sec. The finite element solutions based on Figs. 6(a) and 6(b) are perfectly same. It indicates that the new procedure for liquid region can simulate the ferrostatic pressure independent of deformation of liquid as shown in Fig. 5 due to the large mold taper and thermal contraction of solidifying shell in continuous casting process. In the analysis of continuous cating process, the solidified shell continuously grows with casting time.
Therefore, to apply ferrostatic pressure on solidified shell at each time step as shown in Fig. 6(a), domain under consideration should be constructed into finite element mesh at each time step, which complicate entire analysis procedure. With proposed method, ferrostatic pressure boundary condition can be imposed on growing solidifying shell with simple procedure and no sacrifice of accuracy.

\section{Flow Stress and Thermal Expansion Coefficient in Carbon Steel}

In order to obtain an expression for the flow curves of the carbon steel at various temperatures and strain rates, the following constitutive equation was proposed by Han et al. ${ }^{28)}$

$$
\dot{\varepsilon}_{\mathrm{p}}=A \exp (-Q / R T)[\sinh (\beta K)]^{1 / m}
$$

with

$$
Y_{0}=K \varepsilon_{\mathrm{p}}^{n}
$$

where $A, \beta$ and $\mathrm{m}$ are constants, $R$ is the gas constant, $Q$ is the activation energy for deformation, $K$ is the strength coefficient, $\varepsilon_{\mathrm{p}}$ and $\dot{\varepsilon}_{\mathrm{p}}$ are the effective plastic strain and the effective plastic strain rate, respectively, and $n$ is the strain hardening exponent. Table 3 gives the parameters for $\gamma$-steel and $\delta$-steel obtained by non-linear fitting method based on the experimental data. ${ }^{30,31)}$ In the case of $\delta$-steel, the strain hardening is neglected.

A history of plastic deformation is stored in the material by a certain arrangement of dislocations and it seems reasonable that this history should be lost when the material undergoes a phase transformation. Thus, if a solidifying steel undergoes a $\delta / \gamma$ transformation during deformation, then the accumulated effective plastic strain of $\delta$-steel becomes lost after $\delta / \gamma$ transformation. In this study, the effect of phase transformation on the plastic strain was taken into account. ${ }^{32)}$

In this study, the effective thermal expansion coefficient was calculated as follows

$$
\alpha=\frac{\left(V / V_{\mathrm{ref}}\right)^{1 / 3}-1}{T-T_{\mathrm{ref}}}
$$

where $V_{\text {ref }}$ and $V$ are the specific volume of the material at the reference temperature $T_{\text {ref }}$ and temperature $T$, respectively. Kim et al. ${ }^{21)}$ adopted a solid fraction ${ }^{T} f_{\mathrm{s}}$ 
Table 3. Parameters in Eq. (9) for $\delta$-ferritic and $i$-alustenitic steels.

\begin{tabular}{|cccccc|}
\hline & $\beta\left(\mathrm{MPa}^{-1}\right)$ & $\mathrm{n}$ & $\mathrm{A}\left(\mathrm{sec}^{-1}\right)$ & $\mathrm{Q}(\mathrm{kJ} / \mathrm{mol})$ & $\mathrm{M}$ \\
\hline$\delta$ ferritic Fe & 0.0522 & 0.0 & $9.997 \times 10^{7}$ & 202.1 & 0.2657 \\
$\gamma$ austenitic Fe & 0.01308 & 0.4289 & $1.047 \times 10^{10}$ & 326.3 & 0.2008 \\
\hline
\end{tabular}

Table 4. Specific volume of $\delta$-ferritic, $\gamma$-austentic and liquid steels. ${ }^{35}$ ) The units of specific volume, temperature and carbon content are $\mathrm{cm}^{3} / \mathrm{g}, \mathrm{K}$ and weight percent, respectively.

\begin{tabular}{|l|l|}
\hline & \multicolumn{1}{|c|}{ Specific Volume } \\
\hline$\delta$-ferritic steel & $0.1234+9.38 \times 10^{-6}(\mathrm{~T}-293)$ \\
$\gamma$-austenitic steel & $0.1225+9.45 \times 10^{-6}(\mathrm{~T}-293)+7.688 \times 10^{-6}(\mathrm{C})$ \\
liquid steel & $1 / 7.035$ \\
\hline
\end{tabular}

between the solid fractions at ZDT and ZST and the corresponding temperature at which the solid fraction reaches ${ }^{\mathrm{T}} f_{\mathrm{s}}$ was defined as the liquid impenetrable temperature (LIT) as shown in Fig. 1. It has been known that the solidifying steel begins to behave like solid due to no liquid feeding ${ }^{33)}$ between dendrite arms when the solid fraction becomes larger than a solid fraction of ${ }^{\mathrm{T}} f_{\mathrm{s}}{ }^{1{ }^{18,34)}}$ Thus, the reference temperature for the steel could be chosen to be LIT. In this study, ${ }^{\mathrm{T}} f_{\mathrm{s}}$ is assumed to be $0.8 .^{21.33)}$ The specific volumes for liquid, $\delta$ and $\gamma$ steels were obtained by Wray's data ${ }^{35)}$ as given in Table 4.

\section{Calculation of Heat Transfer}

The temperature distribution in the transverse slice of strand with unit thickness is calculated using Eq. (11) for the 2-dimensional transient heat conduction accompanying the liquid/solid transformation

$$
\frac{\partial}{\partial x}\left(k \frac{\partial T}{\partial x}\right)+\frac{\partial}{\partial y}\left(k \frac{\partial T}{\partial y}\right)+\rho L \frac{\partial f_{\mathrm{s}}}{\partial t}=\rho C_{\mathrm{p}} \frac{\partial T}{\partial t} \ldots
$$

where $T$ is the temperature, $k$ is the thermal conductivity, $C_{\mathrm{p}}$ is the heat capacity, $\rho$ is the density and $L$ is the latent heat. In this study, the enthalpy method ${ }^{36)}$ was used to solve the solidification. The initial and boundary conditions are as follows

$$
T=T_{0}, \quad-k_{n} \frac{\partial T}{\partial n}=q^{\mathrm{s}}
$$

where $T_{0}$ is the initial casting temperature of molten steel, $n$ is the direction normal to strand surface and $q^{\mathrm{s}}$ is the heat flux on the surface. The equation is solved using the finite element method. ${ }^{28}$ ) The following assumptions are used in this calculation.

(1) The heat conduction in the casting direction is negligible compared to the heat flow to mold.

(2) The effect of convective heat flow in liquid region is taken into account using the effective thermal conductivity, $k_{\text {eff }}$, for molten steel. ${ }^{16,37)} k(T)$ is the thermal conductivity of liquid steel at temperature $T$.

$$
k_{\mathrm{eff}}=k(T)\left[1+6\left(1-f_{\mathrm{s}}\right)^{2}\right]
$$

Table 5. Physical data of mold cooling water. ${ }^{391}$

\begin{tabular}{|l|l|}
\hline \multicolumn{1}{|c|}{ Property } & \multicolumn{1}{c|}{ Value } \\
\hline Hydraulic Diameter of Cooling Channel, $D$ & $0.025 \mathrm{~m}$ \\
Flow Velocity of Water, $u_{w}$ & $2.315 \mathrm{~m} / \mathrm{s}$ \\
Specific Heat of Water, $C_{\mathrm{pw}}$ & $4178 \mathrm{~J} / \mathrm{kgK}$ \\
Thermal Conductivity of Water, $k_{w}$ & $0.614 \mathrm{~W} / \mathrm{mK}$ \\
Viscosity of Water, $\mu_{w}$ & $792 \times 10^{-6} \mathrm{Ns} / \mathrm{m}^{2}$ \\
\hline
\end{tabular}

(3) The heat transfer between mold and cooling water is characterized with the aid of a heat transfer coefficient, $h_{w}$, determined from the following dimensionless correlation. ${ }^{38)}$

$$
\frac{h_{\mathrm{w}} D}{k_{\mathrm{w}}}=0.023\left(\frac{\rho_{\mathrm{w}} u_{\mathrm{w}} D}{\mu_{\mathrm{w}}}\right)^{0.8}\left(\frac{C_{\mathrm{pw}} \mu_{\mathrm{w}}}{k_{\mathrm{w}}}\right)^{0.4}
$$

where $D$ is the hydraulic diameter, $u_{\mathrm{w}}$ is the velocity of cooling water, $\mu_{\mathrm{w}}$ is the viscosity of cooling water and $h_{\mathrm{w}}$ is the heat transfer coefficient between mold and cooling water. Thermo-physical data to calculate $h_{\mathrm{w}}$ are given in Table 5. ${ }^{39}$ )

The thermal boundary condition between the solidifying shell surface and the mold wall is modeled using the interfacial heat transfer coefficient, $h_{\mathrm{T}}$, which is a function of air gap thickness and surface temperature of strand. The interfacial heat transfer coefficient can be expressed as follows

$$
h_{\mathrm{T}}=1 / R_{\mathrm{T}}+h_{\mathrm{rad}}
$$

where $h_{\mathrm{rad}}$ is the heat transfer coefficient for the radiative heat flow when the air gaps occur between stand and mold and $R_{\mathrm{T}}$ is the thermal resistance between the strand surface and the mold wall except radiation. The heat transfer coefficient for radiative heat flow, $h_{\text {rad }}$, may be expressed as follows.

$$
h_{\mathrm{rad}}=\sigma \varepsilon\left(T_{\mathrm{s}}+T_{\mathrm{m}}\right)\left(T_{\mathrm{s}}^{2}+T_{\mathrm{m}}^{2}\right)
$$

where $\sigma$ is the Stefan-Boltzmann constant, $\varepsilon$ is the averaged emissivity of the shell and mold surfaces, $T_{\mathrm{s}}$ is the temperature of the shell surface and $T_{\mathrm{m}}$ is the temperature of the mold wall. The averaged emissivity of the shell and mold surfaces, $\varepsilon$, was assumed to be $0.44{ }^{40)}$ The thermal resistance, $R_{\mathrm{T}}$, may be expressed as follows

$$
R_{\mathrm{T}}=R_{1}+R_{2}+R_{3}+R_{4}
$$

The contact resistance between the mold and the mold flux film, $R_{1}$, is given by $R_{1}=1 / h_{1}$, where $h_{1}$ is the contact heat transfer coefficient at the mold surface, ${ }^{41)}$ which was set to $3000 \mathrm{~W} / \mathrm{m}^{2} \mathrm{~K}$. The resistance to conduction through the air gap, $R_{2}$, is calculated by $R_{2}=d_{2} / k_{2}$, where $k_{2}$ is the thermal conductivity of the air and $d_{2}$ is the thickness of the air gap which is calculated from the thermo-elasto-plastic stress analysis. The conductivity of the air ${ }^{39)}$ was set to $0.1 \mathrm{~W} / \mathrm{m} \mathrm{K}$. The resistance to conduction through the mold flux film, $R_{3}$, is calculated by $R_{3}=d_{3} / k_{3}$, where $k_{3}$ is the thermal conductivity of the mold flux and $d_{3}$ is the thickness of the gap filled with mold flux. The conductivity of the mold flux is used 


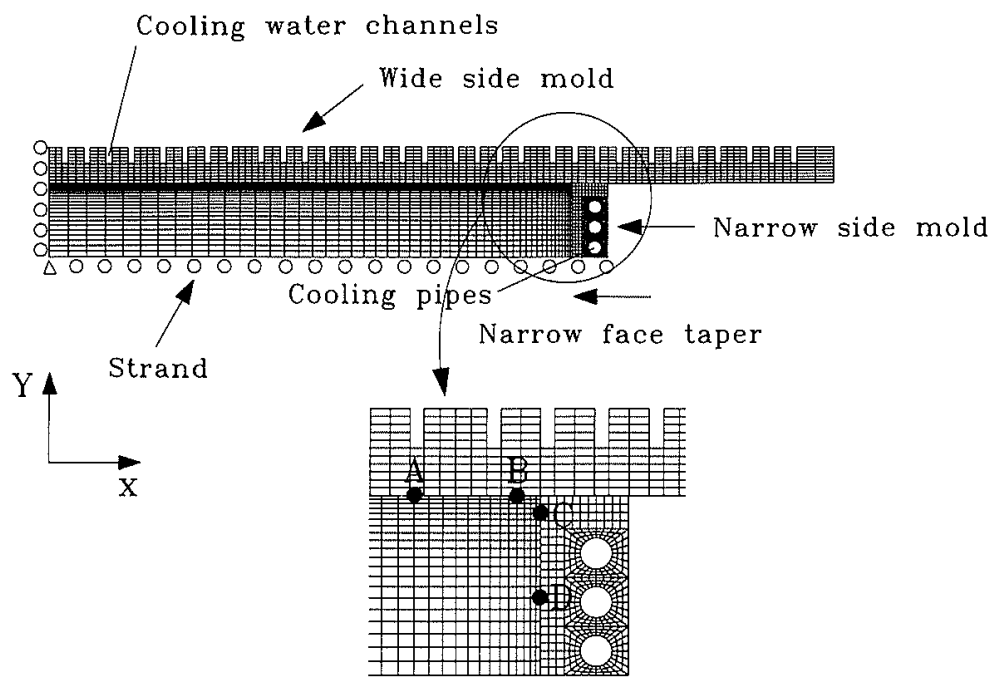

Fig. 8.

Initial finite element mesh for calculating temperature and stress of slab and temperature of mold. The characters, $A, B, C$ and $D$, indicate the positions where the variation of temperature with distances below the meniscus is observed.
Table 6. Temperature dependency of heat transfer coefficient between mold flux and strand surface. ${ }^{11}$

\begin{tabular}{|ccc|}
\hline Temperature Description & Temperature, ${ }^{0} \mathrm{~K}$ & $\mathrm{~h}_{4}, \mathrm{~W} / \mathrm{m}^{2} \mathrm{~K}$ \\
\hline Mold Flux Crystalline Temperature & 1303 & 1000 \\
Mold Flux Softening Temperature & 1423 & 2000 \\
Metal Solidus Temperature & 1723 & 6000 \\
Metal Liquidus Temperature & 1796 & 20000 \\
\hline
\end{tabular}

Table 7. Thermal conductivity, specific heat and latent heat of carbon steel. ${ }^{5.431}$

\begin{tabular}{|ccc|}
\hline $\begin{array}{c}\text { Temperature } \\
\left({ }^{\circ} \mathrm{K}\right)\end{array}$ & $\begin{array}{c}\text { Thermal Conductivity } \\
(\mathrm{W} / \mathrm{mK})\end{array}$ & $\begin{array}{c}\text { Specific Heat } \\
(\mathrm{J} / \mathrm{kgK})\end{array}$ \\
\hline 273 & 30 & 377 \\
473 & 30 & 377 \\
973 & 30 & 554 \\
1373 & 25 & 659 \\
1768 & 33 & 670 \\
1796 & 27 & 673 \\
1823 & 27 & 673 \\
\hline
\end{tabular}

to be $1.0 \mathrm{~W} / \mathrm{m} \mathrm{K}$ and the thickness of the mold flux was set to $100 \mu \mathrm{m}$ from the mold flux consumption and density of mold flux. ${ }^{42)}$ The contact resistance between the mold flux and the steel shell is calculated by $R_{4}=1 / h_{4}$, where $h_{4}$ is the heat transfer coefficient between the mold flux and strand surface. $h_{4}$ must be dependent on temperature due to the large change in viscosities of mold flux over the strand surface temperature range. The temperature dependency of h4 is given in Table 6 .

\section{Application to Continuous Casting of Slab}

Figure 8 shows the initial finite element mesh for calculating the temperature and stress of the $1600 \times$ $220 \mathrm{~mm}$ slab and the temperature of the $\mathrm{Cu}-0.1 \% \mathrm{Ag}$ mold. A quarter section was modeled using symmetry conditions. The finite element calculation for stress analysis was carried out at the plane strain condition. The thermal conductivity of the $\mathrm{Cu}-0.1 \% \mathrm{Ag}$ mold was assumed to be $380 \mathrm{~W} / \mathrm{m} \mathrm{K}^{5}$. Table 7 gives the thermal properties $^{5.43)}$ of the strand as a function of temperature. Calculation was performed at the conditions of a narrow

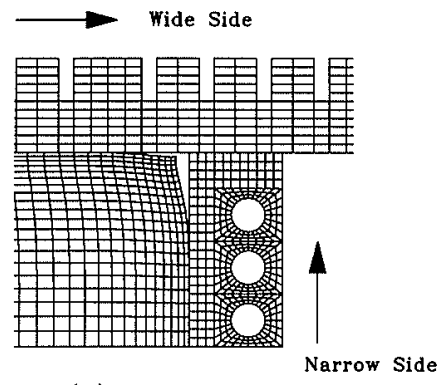

(a) $100 \mathrm{~mm}$

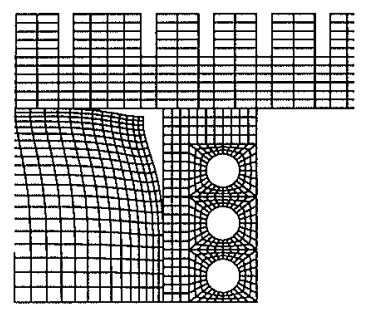

(b) $350 \mathrm{~mm}$

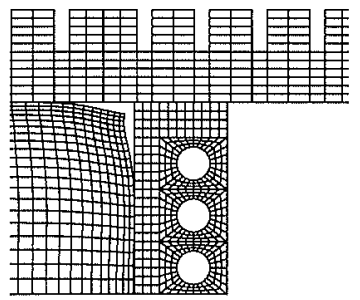

(c) $600 \mathrm{~mm}$

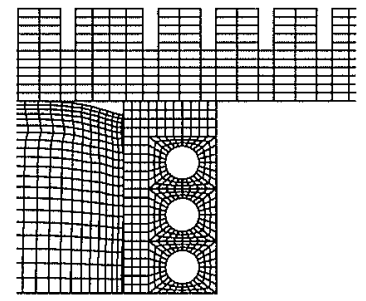

(d) $770 \mathrm{~mm}$ (Mold Exit)
Fig. 9. Deformed geometries of slab and formation of air gap at various distances below the meniscus under the friction coefficient of 0.0 between the solidifying shell surface and mold wall.

side mold taper of $1.5 \% / \mathrm{m}$, a casting speed of $1 \mathrm{~m} / \mathrm{min}$. The distance from meniscus to the mold exit is $0.77 \mathrm{~m}$. The temperature at meniscus was taken as the temperature which is superheated by $20^{\circ} \mathrm{C}$ such as $1543^{\circ} \mathrm{C}$. In order to investigate the effect of contact friction between solidifying shell surface and mold wall on the deformation behavior of strand, the calculation was carried out at the Coulomb friction law with the friction coefficients of $\mu=0$ and 0.2 .

Figures 9 shows the deformed geometries of slab at various distance below meniscus at the friction coefficients of $\mu=0$. The deformed geometries of strand are magnified by 5 times to see the formation of air gap. The air gap was formed on both wide and narrow side corners in early stage of solidification as shown in these figures. The wide side corner of the solidifying shell separated away from the mold wall and air gap became 
larger during the solidification. However, the air gap near the narrow side corner disappeared with the reduction of the slab width by the narrow side mold taper. The slight depression found at the off-corner of the narrow face as shown in these figures. These trends correspond with the severe wear of the narrow side mold which had been observed by other researchers. ${ }^{44,45)}$ Figure 10 shows the observed geometry of the solidifying shell, which was obtained from the break-out shell at a distance below meniscus of $200 \mathrm{~mm} .{ }^{45)}$ As shown in this figure, the shape of solidifying shell are in good agreement with the calculated results that the slight depression occurs at the off-corner of the narrow face.

Figure 11 shows the temperature distributions at various distance below meniscus as the slab moves down through the mold at $\mu=0$. The temperatures of 1523 , 1507 (ZST), 1500 (LIT) and $1450(\text { ZDT })^{\circ} \mathrm{C}$ correspond to the temperatures at which the solid fraction become $0.0,0.6491,0.8$ and 1.0 , respectively. In the initial stage of solidification as shown in Fig. 11(a), the uniform solidifying shell formed on the whole surface of the slab due to the good contact between solidifying shell surface and mold wall at the given friction conditions. However, as solidification proceeded, the shrinkage of the corner region forms the air gap that can be accompanied by

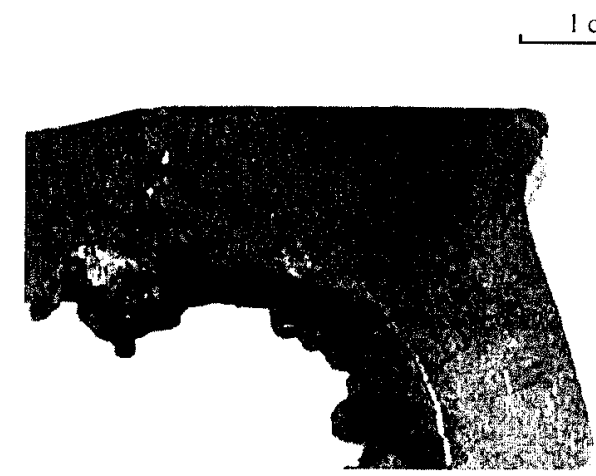

Fig. 10. Experimental shape of break-out steel shell during slab casting at a distance below meniscus of 200 $\mathrm{mm} .{ }^{45)}$

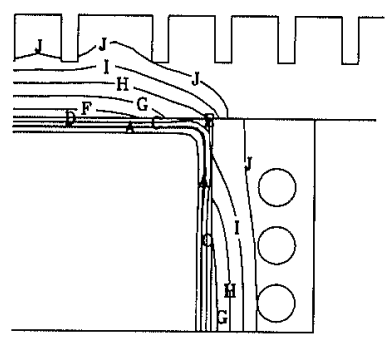

(a) $100 \mathrm{~mm}$

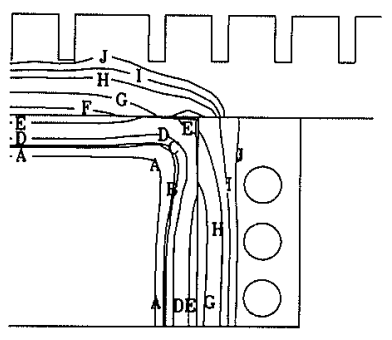

(c) $600 \mathrm{~mm}$

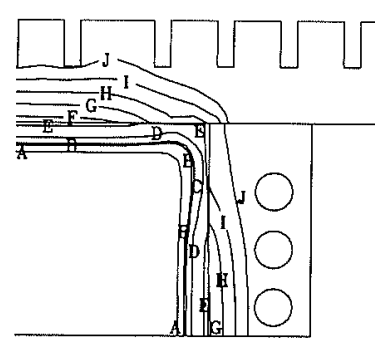

(b) $350 \mathrm{~mm}$

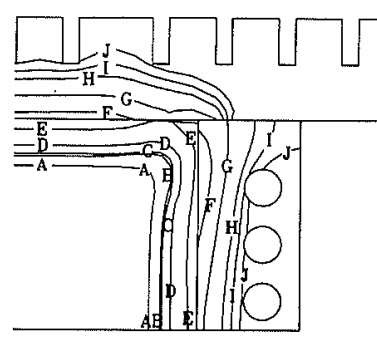

(d) $770 \mathrm{~mm}$ (Mold Exit) hot spot on the off-corner regions of both the narrow and wide side surfaces as shown in Fig. 11(b). The air gap reduced heat flow from strand to mold and gave rise to a thinner shell in these regions which has been observed by previous researchers. ${ }^{4-47)}$

It was reported that all cracks observed in continuously cast steel originate and propagate along the interdendrites in mushy zone except transverse crack. ${ }^{12-17)}$ The ductility loss of the mushy zone is associated with the microsegregation of solute elements at solidifying dendrite interfaces. ${ }^{14,48)}$ This solute enriched region remains as liquid state resulting in decreasing of the ZDT of the steel. The dendrites which have liquid film in its arm space are vulnerable to tensile strain. Thus, the solid fraction at which cracks form, should be defined to investigate this phenomenon in the range of $0<f_{\mathrm{s}}<1$. Clyne et $_{\text {al. }}{ }^{33)}$ proposed the crack susceptibility coefficient to estimate the cracking tendency in continuously cast steel. They divided the mushy zone into the liquid feeding zone and the cracking zone. Cracks which are formed in the liquid feeding zone are refilled with the surrounding liquid, whereas cracks formed in the cracking zone would not be refilled with the liquid because the dendrite arms are compacted enough to resist feeding of the liquid. Kim ef al. ${ }^{11,21)}$ proposed that the threshold solid fraction is ${ }^{\mathrm{T}} f_{\mathrm{s}}$ and the temperature at which the solid fraction reaches ${ }^{\mathrm{T}} f_{\mathrm{s}}$ is defined as the LIT as shown in Fig. 1 . As liquid film between dendrite arm space disappears in the temperature below $\mathrm{ZDT}$, a temperature range, $T_{\mathrm{B}}$, may be defined as ZDT $<T_{\mathrm{B}}<\mathrm{LIT}$. The range $T_{\mathrm{B}}$ indicates the temperature range of cracking zone defined by Clyne et $a l .{ }^{33)}$ In this study, since ZDT and LIT are assumed to be the temperatures where $f_{\mathrm{s}}=1$ and ${ }^{\mathrm{T}} f_{\mathrm{s}}=0.8$, respectively, $T_{\mathrm{B}}$ is defined as $1450^{\circ} \mathrm{C}<T_{\mathrm{B}}<1500^{\circ} \mathrm{C}$. As shown in Fig. 11(b), the region whose temperature is in the range of $1450^{\circ} \mathrm{C}<T_{\mathrm{B}}<1500^{\circ} \mathrm{C}$ was broader at hot spots on the off-corner regions of both the narrow and wide side surfaces than other regions at the middle stage of casting in the mold. It indicates that the possibility of cracking in these regions is larger than that in other
Fig. 11.

Calculated temperature contours in slab and mold at various distances below the meniscus under the friction coefficient of 0.0 between the solidifying shell surface and mold wall. 


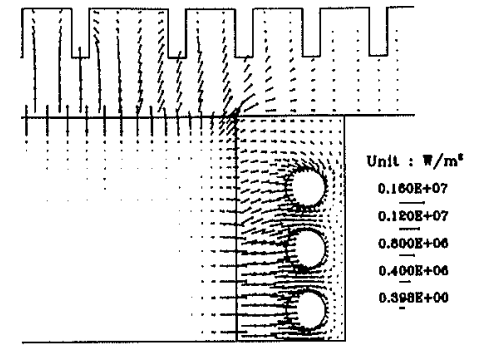

(a) $350 \mathrm{~mm}, \mu=0.0$

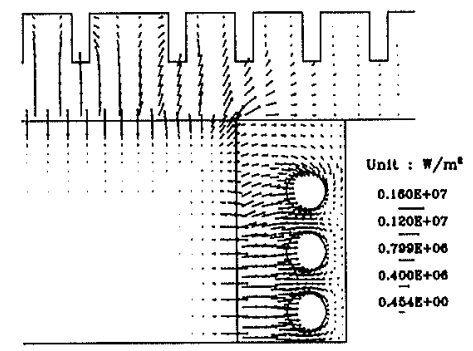

(c) $350 \mathrm{~mm}, \mu=0.2$

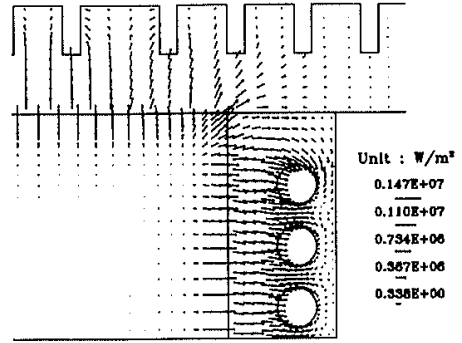

(b) $770 \mathrm{~mm}$ (Mold Exit), $\mu=0.0$

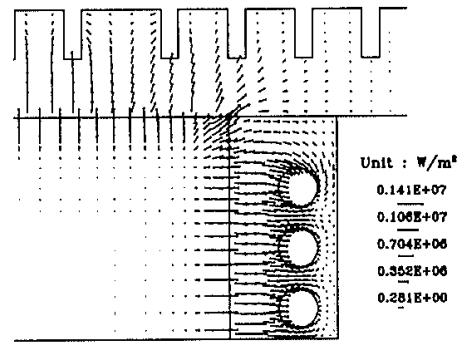

(d) $770 \mathrm{~mm}$ (Mold Exit), $\mu=0.2$
Fig. 12.

Calculated heat flux vectors in slab and mold at various distances below the meniscus under the friction coefficients of 0.0 and 0.2 between the solidifying shell surface and mold wall.

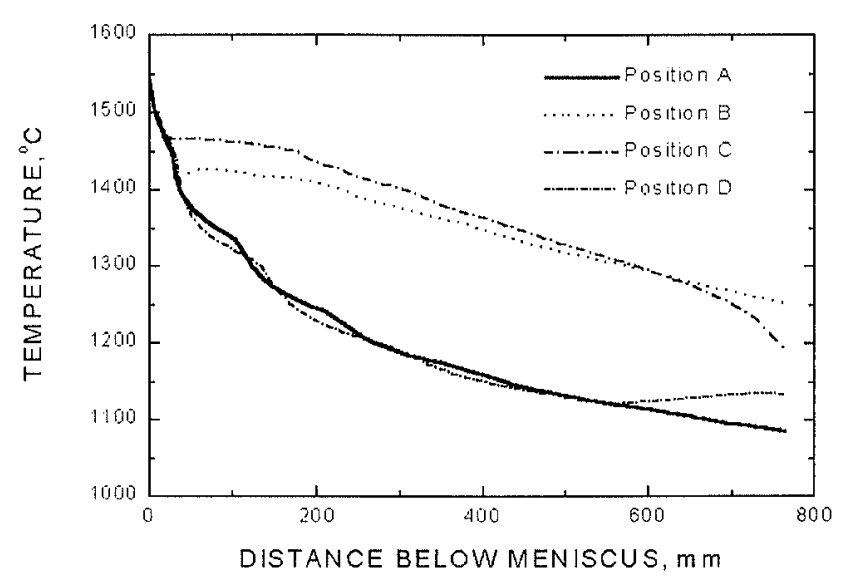

(a)

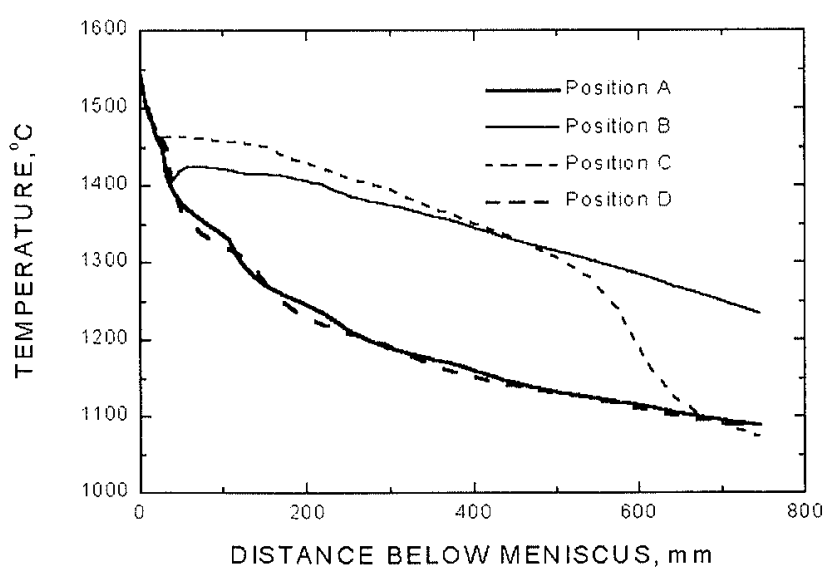

(b)

Fig. 13. Variation of temperature with distance below the meniscus under the friction coefficients of (a) 0.0 and (b) 0.2 between the solidifying shell surface and mold wall. The calculated data are observed at various positions in Fig. 8.

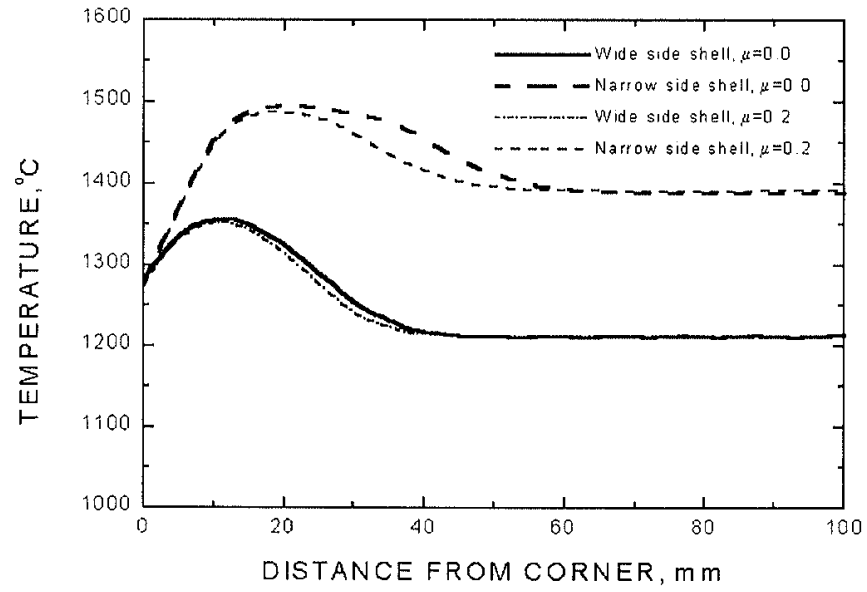

Fig. 14. Calculated temperature distribution of slab surface near slab corner at a distance below the meniscus of $500 \mathrm{~mm}$ under the friction coefficients of 0.0 and 0.2 between the solidifying shell surface and mold wall.

regions due to retarded heat flow cause by the formation of air gap between strand and mold.

Figures 12(a) to 12(d) show the heat flux vectors at $350 \mathrm{~mm}$ below meniscus and the mold exit as the slab moves down through the mold at $\mu=0$ and 0.2 . The mold temperature adjacent to the corner and off-corner regions was lower than other parts of mold, because the air gap reduced the heat flow from strand to mold as shown in Figs. 12(a) to 12(d), while the mold temperature adjacent to narrow side center of strand at which the heat transfer was very large, reached about $130^{\circ} \mathrm{C}$ at the mold exit. When the corner of solidifying shell contacted the narrow side mold wall due to the narrow side mold taper and the corner rotation, ${ }^{44)}$ the heat flow from strand to narrow side mold in this region increased as shown in Figs. 12 (b) and 12 (d) and the decreasing rate of temperature in the mold adjacent to this region conse- 


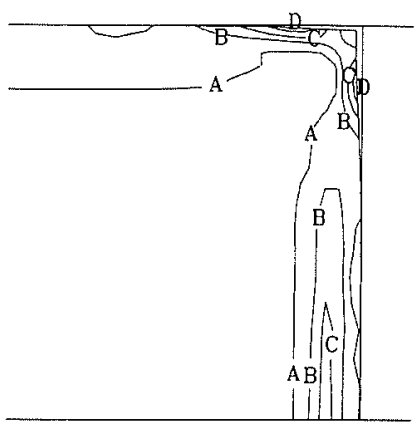

(a)

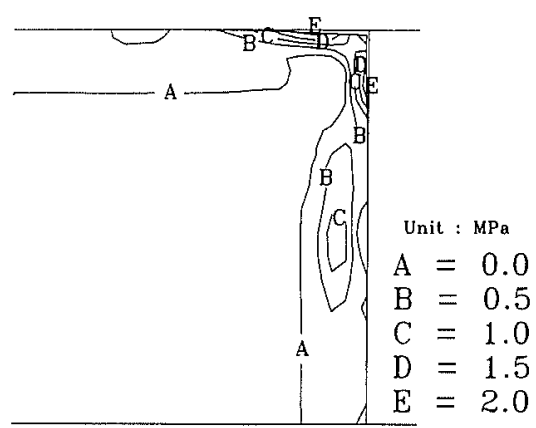

(b)

Fig. 15. Calculated maximum principal stress contour in slab at a distance below meniscus of $500 \mathrm{~mm}$ under the friction coefficient of (a) 0.0 and (b) 0.2 between the solidifying shell surface and mold wall

quently decreased.

Figures 13(a) and 13(b) show the variation of temperature of various positions in strand surface as shown in Fig. 8 with distance below meniscus at $\mu=0$ and 0.2 , respectively. The surface temperatures of positions $A$ and $D$ in Fig. 8 decreased as the solidification proceeds and reached about $1100^{\circ} \mathrm{C}$ at the mold exit. The surface temperatures of the off-corner regions at the positions of $\mathrm{B}$ and $\mathrm{C}$ in Fig. 8 decreased more slowly than those at the positions $\mathrm{A}$ and $\mathrm{D}$ and the hot spot formed on these positions up to distances below meniscus of about $730 \mathrm{~mm}$ at $\mu=0$ and about $550 \mathrm{~mm}$ at $\mu=0.2$, respectively. The slower cooling rate in positions $B$ and $C$ results from the air gap formed between the mold and solidifying shell at a distance below meniscus of about $40 \mathrm{~mm}$ under the given friction conditions. However, the surface temperature of position $\mathrm{C}$ decreased very fast from distances below meniscus of about $730 \mathrm{~mm}$ at $\mu=0$ and about $550 \mathrm{~mm}$ at $\mu=0.2$, respectively. These phenomena result from the contact between the narrow side corner of solidifying shell and the narrow side mold wall due to the corner rotation and the narrow side mold taper. This contact increases the heat flow from strand to mold as shown in Figs. 12(b) and 12(d).

Figure 14 shows the temperature distributions of strand surface along the distance from the corner of slab at the distance below meniscus of $500 \mathrm{~mm}$ at $\mu=0$ and 0.2 . The hot spots formed on the wide and narrow side shells at about $20 \mathrm{~mm}$ from the strand corner. Figures 15(a) and 15(b) show the calculated maximum principal stress distributions in the solidified shell at the distance below meniscus of $500 \mathrm{~mm}$ at $\mu=0$ and 0.2 , respectively. The calculations indicated that a tensile stress of about 2 to $3 \mathrm{MPa}$ developed at about $20 \mathrm{~mm}$ from the corner on both surfaces of the wide and narrow faces. These locations were very close to the hot spots as shown in Fig. 14. The maximum principal stress in the location at $\mu=0.2$ is higher than that at $\mu=0$. This maximum principal stress may encourage longitudinal surface cracks. Thus, the mold flux of high friction coefficient can cause longitudinal surface cracks at the corner of slab. ${ }^{45)}$

\section{Conclusion}

A two-dimensional thermo-elasto-plastic finite element model for the slice of strand in continuous casting process has been developed. The model incorporates the effect of microsegregation of solute elements on hot tears and includes a liquid model, which can consider the ferrostatic pressure due to gravity force. The thermo-mechanical behavior of solidifying shell of slab was analyzed during the solidification in the mold. The calculated results of temperature history, stress distribution and formation of air gap between solidifying shell and mold in continuous casting process of slab were analyzed. The computed temperature distribution and the principal tensile stress distribution well explained the formation of hot spots and cracking at off-corner regions. The distance below meniscus where the slight depression found at off-corner region of the narrow face become shorter with increasing the friction coefficient between solidifying shell surface and mold wall. The hot spots are formed near the wide and narrow side corners. These locations are very close to the large tensile stress regions.

\section{REFERENCES}

1) A. Grill, J. K. Brimacombe and F. Weinberg: Ironmaking Steelmaking, 3 (1976), 38.

2) J. R. Williams, R. W. Lewis and K. Morgan: Int. J. Num. Meth. Engng., 14 (1979), 1.

3) J. K. Brimacombe, F. Weinberg and E. B. Hawbolt: Metall. Trans., 10B (1979), 279.

4) T. C. Tszeng and S. Kobayashi: Int. J. Mach. Tools Manuf., 29 (1989), 121 .

5) J. E. Kelly, K. P. Michalek, T. G. O'Connor, B. G. Thomas and J. A. Dantzig: Metall. Trans., 19A (1988), 2589.

6) J. O. Kristiansson: J. Therm. Stresses, 7 (1984), 209.

7) B. G. Thomas: Proc. Modeling of Casting, Welding and Advanced Solidification Processes VI, ed. by T. S. Piwonka, V. Volller and L. Katgerman, TMS-AIME, Warrendale, PA. (1993), 519.

8) M. R. Aboutalebi, M. Hasan and R. I. L. Guthrie: Steel Res., 65 (1994), 225.

9) K. Kim, Y. Lee, H. N. Han, K. H. Oh and D. N. Lee: Proc. Int. Conf. on Modeling of Casting and Solidification Processes, Hitachi, Japan, (1995), 37.

10) K. Kim, H. N. Han. T. Yeo, Y. Lee, K. H. Oh and D. N. Lee Proc. Melt Spinning Strip Casting and Slab Casting, ed. by E. F. Matthys and W. G. Truckner, TMS, Anaheim, CA, (1996), 87.

11) K. Kim, H. N. Han, T. Yeo, Y. Lee, K. H. Oh and D. N. Lee: Ironmaking Steelmaking, 24 (1996), 249.

12) W. T. Lankford,: Metall. Trans., 3 (1972), 1331

13) F. Weinberg: Metall. Trans. 10B (1979), 219.

14) H. G. Suzuki, S. Nishimura and S. Yamaguchi: Tetsu-to-Hagané, 65 (1979), 2038.

15) T. Matsumiya, T. Sakei, J. Tanaka and T. Ariyoshi: Tetsuto-Hagané, 68 (1982), 1782.

16) G. J. Davies and Y, K. Shin: Proc. Solidification Technology in the Foundry and Casthouse, The Metal Society, London, UK, (1980), 517.

17) J. K. Brimacombe and I.V. Samarasekera: Proc. Principles of Solidification and Materials Processing, Trans. Tech. Publications, New Delhi, (1990), 179.

18) S. Kobayashi: Tetsu-to-Hagané, 73 (1987), s896. 
19) T. Nakagawa, T. Umeda, J. Mutata, Y. Kamimura and N. Niwa: ISIJ Int., 35 (1995), 723.

20) K. Kim, K. H. Oh and D. N. Lee: Scr. Metall. Mater., 34 (1996), 301.

21) K. Kim, T. Yeo, K.H. Oh and D.N. Lee: ISIJ Int., 36 (1996), 284.

22) Y. Ueshima, S. Mizoguchi, T. Matsumiya and H. Kajioka: Metall. Trans., 17B (1986), 845 .

23 ) D. N. Lee and H. S. Kim: Powder Metall., 35 (1992), 275.

24) H. N. Han, H. S. Kim and D. N. Lee: Ser. Metall and Mater., 29 (1993), 1211.

25) H. N. Han, H. S. Kim, K. H. Oh and D. N. Lee: Powder Metall., 37 (1994), 140

26) H. N. Han, H. S. Kim, K. H. Oh and D. N. Lee: Powder Metall., 37 (1994), 259

27) H. N. Han, K. H. Oh and D. N. Lee: Scr. Metall. Mater., 32 (1995), 1937

28) H. N. Han, Y. Lee, K. H. Oh and D. N. Lee: Mater. Sci. Eng, A206 (1996), 81.

29) K. Bathe: Finite Element Procedures, Prentice-Hall International, USA, (1996).

30) The Japan Inst. Met.: Mechanical Behavior of Continuous Casting, Tokyo, (1985), 263

31) P. J. Wray: Metall. Trans., 7A (1976), 1621

32) S. Sjostrom: Mater. Sci. Tech., 1 (1985), 823

33) T. W. Clyne, M. Wolf and W. Kurz: Metall. Trans., 13B (1982), 259.

34) K. Okamura and K. Yamamoto: Proc. Modeling of Casting, Welding and Advanced Solidification Processes VI, ed. by T. S. Piwonka, V. Voller and L. Katgerman, TMS-AIME, Florida,
(1993), 535

35) P. J. Wray: Proc. Modeling of Casting, Welding Processes, ed. by H. D. Brody and D. Apelian, TMS-AIME, Ringe, NH, (1980), 245

36) W. D. Rolph III and K. Bathe: Int. J. Num. Meth. Engng., 18 (1982), 119

37) E. A. Mizikar: Trans. Met. Soc. AIME, 239 (1967), 1747.

38) W. H. Acadams : Heat Transmission, McGraw-Hill, New York, (1954).

39) M. N. Ozisik: Heat Transfer a Basic Approach, McGraw-Hill, Singapore, (1985)

40) S. Susa, K. C. Mills, M. J. Richardson, R. Taylor and D. Stewarst: Ironmaking Steelmaking, 21 (1994), 279

41) W. R. Storkman: Master Thesis, University of Illinois, Urbana, IL, USA, (1990)

42) A. Yamaguchi, K. Sorimachi, T. Sakuraya and T. Fujii: ISIJ Int., 33 (1993), 140.

43) B. G. Thomas, I. V. Samarasekera and J. K. Brimacombe: Metall. Trams., $18 B$ (1987), 119.

44) Y. M. Won, T. Yeo, K. H. Oh, J. K. Park, J. Choi and C.H. Yim: ISIJ Int., 38 (1998), 53.

45) J. K. Park, J. Choi and C. H. Yim: Technical Reports, Iron \& Steel Making Research Team, Technical Research Labs., POSCO Korea, (1996).

46) A. Grill, K. Sorimachi and J. K. Brimacombe: Metall. Trans, 7B (1976), 177.

47) K. Kinoshita, T. Emi and M. Kasai: Tetsu-to-Hagané, 65 (1979), 2022 .

48) P. J. Wray: Metall. Trans., 15A (1984), 2059 